\begin{tabular}{cc} 
MANAGEMENT ISSUES IN & INDUSTRIAL \\
HEALTHCARE SYSTEM & MANAGEMENT \\
\hline
\end{tabular}

\title{
Assessment of the access of the cities of Alborz province to healthcare infrastructure using TOPSIS and MORIS models
}

\author{
Seyyed Javad Sharif Sheykholeslamii ${ }^{*}$, Sara Rahmani ${ }^{2}$, Ali Asghar Yousefi ${ }^{3}$ \\ ${ }^{1,2}$ MS of Executive Management, Management Department, Save Branch, Payame Noor University, \\ Saveh, Arak \\ ${ }^{3}$ MS of Educational Science, Educational Technology Trends
}

\begin{abstract}
Keywords:

Spearman Rank-Order Correlation, Alborz Province, Healthcare Infrastructure, MORIS, TOPSIS

Correspondence: javad.sharif866@gmail.com

Since the health of mind and body is considered as one of the important criteria in the development of regions and countries, therefore, the access to the services as well as its optimal distribution in the regions of the country is of prime importance. In the issue of the equitable access to healthcare services, the first point raised is the access to services. This study aimed to assess the cities of Alborz province in having the healthcare infrastructure. Thus, after extracting indicators for healthcare infrastructure, TOPSIS, MORIS models, and coefficient of the importance were calculated for each of the infrastructures. Finally, by using AHP technique, the cities were ranked in terms of access to healthcare infrastructure. The results obtained for the model indicated that there was a large difference between the province and its cities in terms of access to MORIS and TOPSIS of healthcare infrastructure. In both models, Karaj made the highest and Taleghan city made the least benefit of health infrastructure. Using Spearman rank-order correlation, the correlation between cities' population rank and the rank of having healthcare infrastructure was assessed. The results revealed very poor correlation between these two categories and the distribution of healthcare infrastructure had not been done on the basis of population.
\end{abstract}

\section{Introduction}

Health system is one of the major components of the country which is affected by its economic conditions. At present, governments consider the optimization and appropriate delivery of healthcare services as their most progress; so that, if a country or a community does not resolve the health issue properly, the deficit is seen as one of the weaknesses of 
government and causes widespread dissatisfaction in the community. Considering the nature of health services, the need to these services is not limited to a specific group of people. In fact, all the people in all the settlements are in need of them. The absence or lack of health services, especially in rural areas, small towns, and deprived areas has many consequences. The quantity and quality of public healthcare and enhancing personal and social health is considered as the most important indicators of progress and culture of each country and the success of national development programs largely depends on achieving the goals of the sector. In the issue of the equitable access to healthcare services, the first issue raised, is the access to services itself (Opricovic \& Tzeng, 2004). The equal access to healthcare services has always been the mainstay of researchers in different countries of the world. Therefore, this issue is considered significant in the constitution of our country. In fact, better access to healthcare services for all regions and areas means providing the right services at the right time and in the right places (Hwang \& Yoon, 1981) and access can be considered as a scarce resource that is dependent on redistribution through planning (Hendryx, Ahern, Lovrich \& McCurdy, 2002). The state of healthcare services in developed countries is largely satisfactory but in developing countries due to various reasons such as lack of national health planning, minor healthcare services, and underestimating the health sector, lower resources allocated to this sector. And as such, a wide gap can be seen between developed and developing countries. Even this gap can be observed between the different geographical areas of the Third World countries, so that some cities have appropriated more infrastructures. In contrast, some areas are facing a shortage of healthcare infrastructure. This study was done to rank Alborz Province in terms of its access to health infrastructures. Ranking was done based on health care infrastructure existing in the regions to understand the differences and determine services required and adjust inequality between them. Proper utilization of the infrastructures depends on accurate identification and classification of resources, facilities, services, and capacity in each region and area.

\section{The Literature Review}

The importance and the role of access to healthcare services and optimal use and distribution of healthcare resources and infrastructures was an intrigue to conduct some extensive studies to determine their level and its contributions in different healthcare grounds.

Contractor (2008) conducted a study in a resettled slum community in India to find the impact of involuntary resettlement on issues concerning women's health. It discusses gender differentials in gaining access to healthcare. The findings showed that it is required to develop an integrated planning which provides the possibility for women to access to healthcare services.

Roberts (2009) in his investigation tried to explore the reason of moving countries from public to private financing of healthcare. The results showed that moves towards private financing is better accounted for by the differences in availability to the policymaking part of the state and health policymakers should focus on more reforms on this part by drawing reformers' attention.

Since user satisfaction with healthcare service performance is considered as an important outcome, in a study done by Croker and Campbell (2009), some qualitative methods were 
used to explore patients' and practitioners' satisfaction with access to healthcare services in a remote island setting. The findings revealed that patients did not receive that much equitable provision of services. There were some obstacles to using those services and there were some concerns about both patients' and practitioners' outlook such as expectations, choice, and patient-practitioner relationships.

Wendt (2009) presented expenditures, financing, provision, and access to healthcare in 15 European countries as typology of healthcare systems. On this basis, he constructed three types of healthcare system, namely a health service provision-oriented type, a universal coverage- controlled access type, and low budget - restricted access type. The typology tried to make a better link between institutional structures and health outcomes and improve patients' access to necessary healthcare services.

Archibald and Rankin (2013) investigated how community-based resource constraints including socioeconomic privation, racial and ethnic isolation, and limited healthcare infrastructure affect the provision of healthcare services in the United States. They found that counties with higher socioeconomic privation and decreased healthcare infrastructure have limited access to healthcare services. However, counties with a higher amount of racial and ethnic minority members did not experience less access to healthcare services.

Since financial protection as part of healthcare has main role in the health systems of the world, Kisa and Younis (2013) offered a financing method for the poor in Turkey known as the Green Card system which has many successes as a permanent insurance program and provided opportunities for the poor to have access to medical care.

Arnold, Theed, and Gagnon (2014) aimed to identify urban migrants' barriers to accessing healthcare in Nairobi compared with barriers confronted by Kenyans who live in the same place. They defined a conceptual framework for assessing access to healthcare which includes availability, geographic accessibility, financial accessibility, and acceptability. Regular obstacles to accessing care that were shared and divided by migrants and Kenyans involved waiting times, drug availability, transportation, and cost. The results revealed that the barriers for migrants include threat of annoyance, cost differences between migrant and Kenyan patients, some discriminations, and language barriers. Sandahil, Norredam, Hjern, Asher, and Nielsen (2013) contrasted policies concerning access to healthcare services that is composed of physical examination and examining mental health problems of accompanied asylum-seeking children in the Nordic countries. The findings indicated that availability to healthcare services for these children is different in the Nordic countries.

Stan (2015) investigated the relationship between migrants' transnational healthcare practices and inequalities in availability to healthcare services in migrants' their origin countries and also their destination country and it also tried to find the role of healthcare privatization to these inequalities. It reflected that migrants' transnational healthcare practices are considered as approaches to migrants' social mobility which also reflects the increasing privatization of healthcare services in origin and destination country.

Rhodes, Song, Namb, Choi, and Choi (2015) employed community-based participatory research (CBPR) to identify barriers to healthcare access and find effective strategies to increase healthcare access among Korean community in North Carolina (NC). They 
recognized practical barriers to health care, negative perceptions about care, contingencies for care, and provider misconceptions about local needs (Rhodes et al., 2015).

\section{The Study}

One of the main pillars of development is the social development. The purpose of social development is to provide the physical, economic, and social facilities for all people in the society to increase the community access to vital resources and its fair distribution. So, it can be said that the objective for the development is improve living standards and quality of life of the community and its coordination with the country's economic development. Social development includes growth in the social aspects of life such as health care, education, nutrition, and employment which supplies social welfare and its goals in general (Zahedi Asl, 2002). Health development should be viewed as an inseparable part of social development which should have clear objectives, policies, and programs and each country should adopt a policy based on the objectives and programs (Amer, 2007) providing healthcare services to all people in the society. International society for equity in health defines justice as the lack of systematic and potential differences in one or more aspects of health in a population as well as in economic, social, demographic, and geographic subgroups based on definitions of justice. Social justice is achieved when health care be distributed based on individual needs; thereby, the definition of justice implies the definition of access and the definition of need, too (Gulliford \& Morgan, 2003). Thus, access to healthcare services will provide the background for establishing justice in society and the right to gain healthcare services would create equal opportunities for all people in the society (Nikpour, Asefzadeh, \& Majlesi, 1989). One of the major problems in providing health services in developing countries is the lack of resources and facilities as well as poor distribution of health human resources in rural and urban areas. The development of public health is influenced by various factors including social, political, cultural, and demographic (Salarian, 2007). This imbalance in supply and demand of health human resources causes the lack of efficiency in the provision of services. False organizing of forces contributes to this lack of efficacy, too (Nikpour, 2006). To fix the problem, the community health needs and requirements must be identified. In fact, without identifying these needs, health services cannot be fully provided. In addition to providing healthcare, a balanced and optimal distribution of these services to all people is necessary which is obtained by utilizing various models based on the demographic weight of each area. This study tried to focus on health infrastructures and their spatial distribution within the cities of Alborz Province to rank the city of Alborz province in terms of access to health services and review the correlation of distribution of healthcare infrastructure with the population distribution (Delgoshaei, Tabibi, \& Pahlavan, 2008).

According to the latest administrative divisions in 2012, Alborz province with an area of 5142 square kilometers consisted of 5 cities, 11 districts, 16 towns, and 25 rural districts, and 354 villages with inhabitants. The main cities of Alborz province include Karaj, Savojbolagh, Nazar Abad, Taleghan, and Eshtehard. This province from the north is limited to the Mazandaran province from the east to Tehran province, from the south to the Markazi province, from the west to Qazvin province. Alborz Province is located between ridge folds of the Markazi province and the western edge of Dasht Kavir and the climate is mainly 
influenced by the altitude factor. Karaj and Savojbolagh with 1483 square kilometers and Nazarabad with 587 square kilometers had the highest and lowest areas. According to the latest population and housing census in November 2011, the population of Alborz Province was $2,412,513$ people $(7 / 50 \%$ males and $3 / 49 \%$ female). In the same year, the largest population in the age group $29-25$ years was 302286 people (12.5\% of the total population). In addition, among 719,464 households living in Alborz province, 7/90\% has been settled in urban areas and 3/9 percent in rural areas. In 2012, births registered in the province were 35649 people of which about $4 / 51 \%$ was male and $6 / 48 \%$ was female.

\section{Method}

Due to the nature and aims of the research, the approach of research was descriptive. Thus, firstly, the required information and statistics related to the healthcare infrastructure for determining the AHP level of the cities were collected and then through the model, the importance of the underlying criteria of each factor was calculated. Finally, the results of this model were computed and high-ranked cities and MORIS and TOPSIS of the related measures in terms of utilizing healthcare infrastructures were identified. After the identification and ranking of cities, the correlation between population rank and the rank of having healthcare infrastructure using Spearman model was calculated.

\section{Population Ranking}

In the current study, to evaluate the correlation between the distribution of healthcare infrastructure and the population rank, the population ranking of Alborz cities was done. In terms of population, Karaj and Savojbolag are the first and second and Savadkouh and Juybar are ranked 15 and 16 , respectively.

\section{Population}
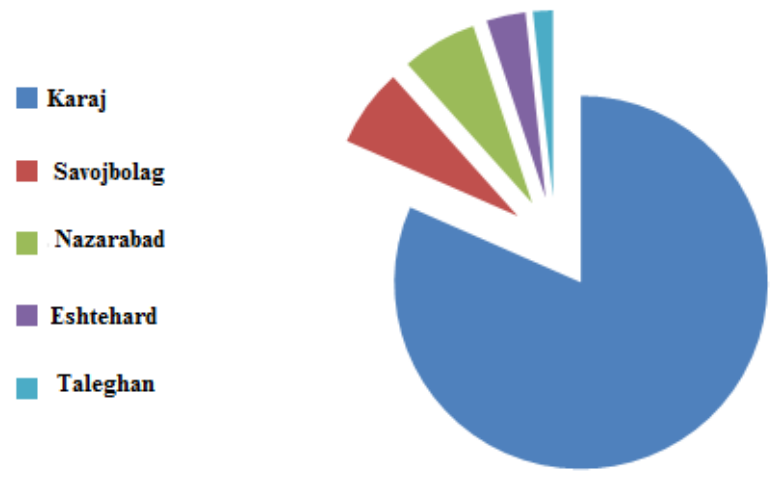

Figure 1. The population rank of Alborz province 


\section{The MORSIS Model}

This method has eight steps which are summarized as follows:

- Setting the indicators table (in the first column, the settlements and in the next column, indicator);

- Standardization of the numbers in the indicator table by Morris uneven coefficient equation.

Equation 1: Morris uneven coefficient

$$
y i j=\frac{X i j-X \min }{X \max -X \min }
$$

$Y_{i j}=$ Morris uneven coefficient (Uneven indicators for the variable $\mathrm{i}$ in the unit $\mathrm{j}$ )

$\mathrm{X}_{\max }=$ maximum values of the variables in each column

$\mathrm{X}_{\mathrm{ij}}=$ the number of variables

$X_{\min }=$ minimum values of the variables in each column

Ranking of numbers obtained from Morris uneven coefficient, thereby the largest number awarded first rank and this rank is representative of more facilities in habitats.

Calculating final coefficients of development through the following equation:

Equation 2: final coefficients of development

$$
D I .=\frac{\sum_{i=1}^{n} y i j}{n}
$$

$\Sigma Y_{i j}=$ sum of the uneven coefficients of development

$\mathrm{N}=$ number of indicators

Final ranking of settlements according to the numbers obtained from the coefficient of development and ranking of the settlements; whatever the number di is greater, development of the settlements is more (Amer, 2007).

\section{TOPSIS Techniques (Ranked by Similarity to Ideal Solution)}

This technique proposed by Hwang and Yoon (1981) as the best proposal which is similar to an ideal solution. It meant that alternative options must have the shortest distance from the positive ideal solution and yet the farthest distance from the negative ideal solution. TOPSIS as a multi-criteria decision-making method is a simple but efficient method for prioritizing. The principle behind this model is that the option is considered to be the minimum Euclidean distance from the ideal solution and at the same time the farthest from the negative ideal solution (Shin, 2003).

Sometimes an option is in the minimum distance from the ideal solution. On the other hand, it has a shorter distance from the negative ideal solution than the other options. The model assumes that each indicator in the decision making matrix has more uniform increasing or decreasing desirability.

The advantages of this method are simultaneous use of both quantitative and qualitative criteria in it; output of the model can determine the order of priority options: the contrast and the match of the options are considered; the results of this model is consistent with 
experimental methods; it has the criteria and indicators of the initial weighting coefficients; and the method is simple and has appropriate speed.

\section{Steps of TOPSIS Technique}

The process and algorithm of technique which is ranked by similarity to ideal solution in eight steps can be summarized as follows:

Step 1: Formation of matrix data based on alternative $\mathrm{n}$ and indicator $\mathrm{k}$

These indicators which are considered as the healthcare infrastructure include active health and medical centers, active health sites, medical laboratories, health clinics, emergency centers, the number of beds in health institutions, the number of hospitals, the number of pharmacies, the number of dentist general practitioner and specialist and dentist.

\section{Creating an Initial Matrix}

Table 1 shows the indicators used in the ranking of Alborz province in terms of healthcare infrastructure.

Table 1

Indicators Used in the Ranking of Alborz Province in terms of Healthcare Infrastructure

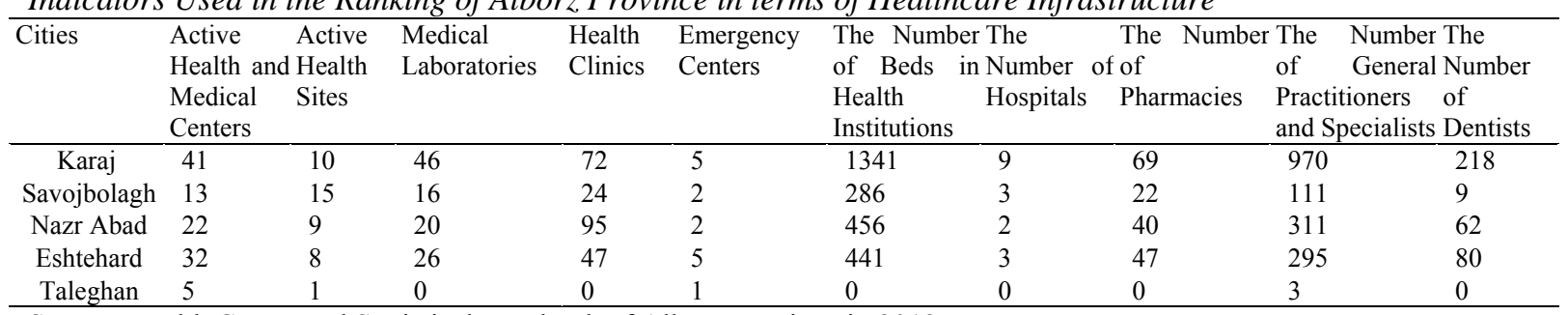

Source: Health Center and Statistical Yearbook of Alborz Province in 2012

All measures should be uniform, which is either all positive or all negative. If the indicator is negative, it cannot be tested by positive measures.

Step 2: Preparing normalized matrix

Due to the strong possibility of not allocating a small amount to criteria and indicators of a unit, the unit dimensions must be eliminated and these quantified amounts are transformed to dimensionless values. Therefore, all amounts accruing to the matrix elements of decisionmaking should be transformed to dimensionless amounts based on the following formula.

Step 3: At this step, it is possible to validate each indicator based on personal views, perspectives, expertise, and also the importance of each criterion using weighting models like Linmap model, AHP model, and Antropi model (Chu, Shyu, Tzeng, \& Khosla, 2007). It should be noted that the total weight of the criteria must be equal to 1 , that is:

$$
\sum_{i}^{n} w_{i}=1
$$


In this study, AHP model was used to weigh each criterion and the weight of each criterion is shown in Table 2.

Table 2

Weighing to the Criteria Used in TOPSIS and MORIS Models Using AHP

\begin{tabular}{|c|c|c|c|c|c|c|c|c|c|c|}
\hline CR & $\begin{array}{c}\text { Active } \\
\text { Health and } \\
\text { Medical } \\
\text { Centers }\end{array}$ & $\begin{array}{c}\text { Active } \\
\text { Health } \\
\text { Cites }\end{array}$ & $\begin{array}{c}\text { Medical } \\
\text { laboratories }\end{array}$ & $\begin{array}{l}\text { Health } \\
\text { Clinics }\end{array}$ & $\begin{array}{c}\text { Emergency } \\
\text { Centers }\end{array}$ & $\begin{array}{l}\text { The Number } \\
\text { of Beds in } \\
\text { Health } \\
\text { Institutions }\end{array}$ & $\begin{array}{l}\text { The } \\
\text { Number of } \\
\text { Hospitals }\end{array}$ & $\begin{array}{c}\text { The Number } \\
\text { of } \\
\text { Pharmacies }\end{array}$ & $\begin{array}{l}\text { The Number } \\
\text { of General } \\
\text { Practitioners } \\
\text { and Specialists }\end{array}$ & $\begin{array}{l}\text { The } \\
\text { Number of } \\
\text { Dentists }\end{array}$ \\
\hline 0.02 & 0.26 & 0.109 & 0.139 & 0.877 & 0.074 & 0.046 & 0.196 & 0.21 & 0.158 & 0.144 \\
\hline
\end{tabular}

Source: The authors' review of the Statistical Yearbook of Alborz Province in 1391

Then, the number of each criterion is multiplied in the same weight and standard data matrix is determined after weighing. Here, in order to weigh, step two of the Analytic Hierarchy Process method was used to determine the importance of each criterion on 9 hourly-Quantitative scales.

Step 4: Using standard matrix of phase 3 (standardized weighted matrix), the highest performance of any indicator which is shown by $\left(\mathrm{A}^{*}\right)$ was determined as follows:

$$
\begin{aligned}
A^{+} & =\left\{v_{1}^{+}(\boldsymbol{x}), v_{2}^{+}(\boldsymbol{x}), \ldots, v_{j}^{+}(\boldsymbol{x}), \ldots, v_{m}^{+}(\boldsymbol{x})\right\} \\
& =\left\{\left(\max _{k} v_{k j}(\boldsymbol{x}) \mid j \in J_{1}\right),\left(\min _{k} v_{k j} \mid j \in J_{2}\right) \mid k=1, \ldots, n\right\},
\end{aligned}
$$

Step 5: The lowest performance of any indicator which is shown by (A-) was determined as follows:

$$
\begin{aligned}
A^{-} & =\left\{v_{1}^{-}(\boldsymbol{x}), v_{2}^{-}(\boldsymbol{x}), \ldots, v_{j}^{-}(\boldsymbol{x}), \ldots, v_{m}^{-}(\boldsymbol{x})\right\} \\
& =\left\{\left(\min _{k} v_{k j}(\boldsymbol{x}) \mid j \in J_{1}\right),\left(\max _{k} v_{k j}(\boldsymbol{x}) \mid j \in J_{2}\right) \mid k=1, \ldots, n\right\},
\end{aligned}
$$

\begin{tabular}{|c|c|c|c|c|c|c|c|c|c|c|}
\hline Indicator & $\begin{array}{c}\text { Active } \\
\text { Health and } \\
\text { Medical } \\
\text { Centers }\end{array}$ & $\begin{array}{c}\text { Active } \\
\text { Health } \\
\text { Cites }\end{array}$ & $\begin{array}{c}\text { Medical } \\
\text { laboratories }\end{array}$ & $\begin{array}{l}\text { Health } \\
\text { Clinics }\end{array}$ & $\begin{array}{c}\text { Emergency } \\
\text { Centers }\end{array}$ & $\begin{array}{l}\text { The Number } \\
\text { of Beds in } \\
\text { Health } \\
\text { Institutions }\end{array}$ & $\begin{array}{l}\text { The } \\
\text { Number of } \\
\text { Hospitals }\end{array}$ & $\begin{array}{l}\text { The Number } \\
\text { of Pharmacies }\end{array}$ & $\begin{array}{c}\text { The Number of } \\
\text { General } \\
\text { Practitioners } \\
\text { and Specialists }\end{array}$ & $\begin{array}{l}\text { The } \\
\text { Number of } \\
\text { Dentists }\end{array}$ \\
\hline $\begin{array}{l}\text { vmax } \\
(\mathrm{A}+)\end{array}$ & 559 & 0.839 & 0.88 & 0.36 & 0.24 & 50.7 & 1.24 & 0.80 & 1236 & 2.32 \\
\hline $\begin{array}{c}\mathrm{v} \min \\
(\mathrm{A}-)\end{array}$ & 0.08 & 0.004 & 0 & 0 & 0.007 & 0 & 0 & 0 & 0.001 & 0 \\
\hline
\end{tabular}

Table 3

Calculation of the Highest and Lowest Performance of Any Indicator

Source: The authors' review of the Statistical Yearbook of Alborz Province in 2012

Step 6: To determine the criteria of distance for the minimum and maximum alternative, the following formula was used: 


$$
\begin{aligned}
& d_{i}^{+}=\sqrt{\sum_{j=1}^{n}\left(V_{i j}-V_{j}^{+}\right)^{2}} \\
& d_{i}^{-}=\sqrt{\sum_{j=1}^{n}\left(V_{i j}-V_{j}^{-}\right)^{2}}
\end{aligned}
$$

Step 7: In this step, a coefficient which is equal with the division of minimum and maximum alternative is obtained. In other words, a relative vicinity of (Ai) to $\left(\mathrm{A}^{*}\right)$ was calculated as follow:

$$
C L_{i}^{*}=\frac{d_{i}^{-}}{d_{i}^{-}+d_{i}^{+}}
$$

Step 8: Ranking of options is based on the descending order of cli+. Ranking has fluctuated between zero and one. In this regard, cli $+=1$ represents the highest rank and cli $+=0$ represents the lowest rank.

Table 4

Final Ranking of Alborz Province's Cities based on the Model

\begin{tabular}{cccccc}
\hline Cities & di + & di- & Cli+ & The Rank of TOPSIS & The Rank of MORIS \\
\hline Karaj & 53775069 & 133544071 & 0.995989384 & 1 & 1 \\
Savojbolagh & 131.180858 & 2.983097035 & 0.022234713 & 3 & 4 \\
Nazr Abad & 1195427621 & 14.07134067 & 0.105313289 & 2 & 2 \\
Eshtehard & 1208006114 & 13.14432452 & 0.098132299 & 4 & 3 \\
Taleghan & 1335568372 & 0 & 0 & 5 & 5 \\
\hline
\end{tabular}

Source: The authors' review of the Statistical Yearbook of Alborz Province in 2012

According to the results of TOPSIS model, the cities of Karaj, Savojbolagh, Eshtehard, Taleghan and the cities Karaj, Nazr Abad, Eshtehard, Savojbolagh, Taleghan in MORIS model were ranked first to fifth, respectively. Then, the correlation between population rank and the rank of access to healthcare infrastructure using MORSIS model was assessed.

Table 5

Calculation between Population Rank and TOPSIS Rank of the City Using Spearman Correlation Coefficient

\begin{tabular}{lcccc}
\hline Cities & Population Rank & TOPSIS Rank & D & D2 \\
\hline Karaj & 1 & 1 & 0 & 0 \\
Savojbolagh & 2 & 3 & -6 & 36 \\
Nazar Abad & 3 & 2 & 0 & 0 \\
Eshtehard & 4 & 4 & 0 & 0 \\
Taleghan & 5 & 5 & -10 & 100 \\
\hline
\end{tabular}




$$
\begin{aligned}
& \sum \mathrm{d}^{2}=485 \\
& \mathrm{r}=1-\frac{6 \sum d^{2}}{n^{3}-n}=>r=1-\frac{6 \times 485}{4096-16}=0.2868
\end{aligned}
$$

The result of Spearman rank showed the correlation between population rank and the rank of access to healthcare infrastructure in the TOPSIS model was $0 / 28$ compared to the MORIS model which was $0 / 24$. The correlation indicated that the distribution of healthcare infrastructure was not according to population and there must be a review of the distribution of healthcare infrastructure in the Alborz province.

\section{Discussion and Conclusion}

One of the basic needs of human communities is the need to appropriate and timely access to healthcare services that is attainable only in the shadow of the appropriate distribution of these facilities. In this paper, according to the healthcare infrastructures of the cities of Alborz Province, firstly, the importance coefficient of each infrastructure was calculated based on AHP model and then using MORIS and TOPSIS models, the cities were ranked. The results of both models indicated that the city of Karaj had the highest healthcare infrastructure and Taleghan had the lowest. Then, the population of Alborz province was ranked and Spearman model was used to evaluate the correlation between population ranks of cities in having healthcare infrastructure. The results obtained from the Spearman model in both TOPSIS $(28 / 0)$ and MORIS (29/0) showed a weak correlation between the rank of population and the access to healthcare infrastructure. The results revealed that the city of Alborz, in terms of health indicators, were not similar and were very different and most of them in terms of the healthcare indicators of development were not desirable. The most important factor in the unequal distribution of healthcare services was the policies and planning that lead to the centralization of activities and services in the great cities of this province. This centralization arose the disputes for health developments in cities more and more. Therefore, to provide the equal healthcare services for all people, it is of prime importance to have a plan in place for optimum distribution of healthcare infrastructures. According to the results, it is suggested that in the first phase, the provinces that have less availability to these indicators, take priority in the allocation of funds. In the next step, paying attention to the development of healthcare services in the cities of the province over a medium-term program seems necessary. And finally, increasing the availability to healthcare indicators in the entire cities of this province is important in long term. Thus, reducing the gap in access to healthcare indicators in the cities of the province will occur hierarchically and on a regular basis, it should pay more attention to the cities that have lower healthcare infrastructure and schedule for their development should be provided, too. Centralizing of health facilities and services in cities that have high infrastructure should also be avoided. Creating incentives for investment in private sector is essential. As well as providing appropriate grounds to attract specialists in the cities that are in the lower ranks, having healthcare infrastructures is imperative. 


\section{References}

Alborz Statistical Yearbook in 1391. (2012). Statistical Center of Iran, Iran.

Amer, S. (2007). Towards Spatial Justice in Urban Health Services Planning: A spatial-nalytic GIS-based approach using Dar es Salaam, Tanzania as a case study (Unpublished doctoral dissertation). International Institute for Geo-Information Science and Earth Observation. Enschede, The Netherlands.

Archibald, M. E., \& Rankin, C. P. (2013). A spatial analysis of community disadvantage and access to healthcare services in the U.S. Social Science \& Medicine, 90, 11-23.

Arnold, C., Theed, J., \& Gagnon, A. (2014). A qualitative exploration of access to urban migrant healthcare in Nairobi, Kenya. Social Science \& Medicine, 110, 1-9.

Chu, M. T., Shyu, J. Z., Tzeng, G. H., \& Khosla, R. (2007). Comparison among three analytical methods for knowledge communities group-decision analysis. Expert Systems with Applications, 33(4), 1011-1024.

Contractor, Q. (2008). Understanding the impact of involuntary slum resettlement on women's access to healthcare in Mumbai, India. Journal of Comparative Social Welfare, 24(2), 153-163.

Croker, J. E., \& Campbell, J. L. (2009). Satisfaction with access to healthcare: Qualitative study of rural patients and practitioners. Primary Health Care Research \& Development, 10, 309-319.

Delgoshaei, B., Tabibi, J., \& Pahlavan, P. (2008). Model of human resource development in health sector of Iran. Journal of Research in Medical, 31, 311-325.

Gulliford, M., \& Morgan, M. (2003). Access to health care. London: New York, Routledge.

Hendryx, M., Ahern M., Lovrich, N., \& McCurdy, A. (2002). Access to health care and community social capital. Health Service Research, 37(1), 85-101.

Hwang, C. L., \& Yoon, K. (1981). Multiple attribute decision making: Methods and applications. New York: SpringerVerlag.

Kisa, A., \& Younis, M. Z. (2013). Access to healthcare: Lessons from Turkey. International Journal of Health Promotion \& Education, 45(2), 53-60.

Nikpour, B., Asefzadeh, S., \& Majlesi, F. (1989). Management and planning of healthcare. Tehran: Tehran University Press.

Nikpour, B. (2006). Healthcare in the villages of Chaharmahal and Bakhtiari. Tehran: Tehran University Press.

Opricovic, S., \& Tzeng, G. H. (2004). Compromise solution by MCDM methods: A comparative analysis of VIKOR and TOPSIS. European Journal of Operational Research, 156(2), 445-455.

Rhodes, S. D., Song, E., Namb, S., Choi, S. J., Choi, S. (2015). Identifying and intervening on barriers to healthcare access among members of a small Korean community in the southern USA. Patient Education and Counseling, 98(4), 484-491.

Roberts, A. (2009). The Politics of healthcare reform in post communist Europe: The importance of access. Journal of Public Policy, 29(3), 305-325.

Salarian, A. (2007). A conceptual framework for achieving the equity indicators in health sector of social security organization. Social Security Quarterly, 9(28), 43-80.

Sandahl, S., Norredam, M., Hjern, A., Asher, H., \& Nielsen, S. S. (2013). Policies of access to healthcare services for accompanied asylum-seeking children in the Nordic countries. Scandinavian Journal of Public Health, 41(6), 630-636.

Shin, H. (2003). Income related inequity in health care access and delivery (Unpublished doctoral dissertation). University of South Carolina, USA.

Stan, S. (2015). Transnational healthcare practices of Romanian migrants in Ireland: Inequalities of access and the privatization of healthcare services in Europe. Social Science \& Medicine, 124, 346-355.

Wendt, C. (2009). Mapping European healthcare systems: a comparative analysis of financing, service provision and access to healthcare. Journal of European Social Policy, 19(5), 432-445.

Zahedi Asl, M. (2002). Foundations of social welfare. Tehran: Allameh Tabatabai University Press. 